\title{
Characteristics of Ultrasonic Wave Dolphins for Autism Therapy
}

\author{
Herlinawati $^{1}$, Umi Murdika ${ }^{2}$, Renyep Proborini ${ }^{3}$ \\ ${ }^{1,2}$ Departement of Electrical Engineering \\ University of Lampung \\ ${ }^{3}$ University of Muhammadiyah Lampung \\ Bandar Lampung, Indonesia \\ ${ }^{1}$ herlinawati.rusydi@yahoo.com \\ 2umimurdika@yahoo.com \\ ${ }^{3}$ rproborinilyahoo.com
}

Abstract - Autism has been neurobiology developmental disorder experienced by a person since birth or toddler that makes him unable to form social interaction and communication (language and speech), having emotional behavior problems, sensory and motoric disturbances and abnormal or delayed development. This condition leads people with autism to being insulated with other persons and entering the repetitive world, obsessive activities and interests. Autism therapy using dolphins to produce ultrasonic waves of certain frequencies can help aligning the work function of motor and sensory nerves of people with autism. Detection and analysis of the characteristics of ultrasonic waves generated by dolphins on several conditions required to remove the background noises created by water and breathing sound from a dolphin (hiss and noise reduction).

Keyword - Autism, Neurobiology, Interaction, Sensory, Ultrasonic

\section{INTRODUCTION}

Autism is a neurobiology developmental disorder experienced by a person from the moment of birth or infancy, which makes him unable to form social relationships or normal communication. As a result, the child will be isolated from other human being and entering into the world and repetitive, obsessive activities and interests [1]. According to [2], the characteristics of children with autism are experiencing disruptions in 6 areas : social interaction, communication (language and speech), emotional behavior, patterns of play, sensory and motoric disturbances, and delayed or abnormal development.

One of the treatments of patients with autism who have recognized the medical world is dolphin therapy [3]. Dolphins are highly intelligent marine mammals and its body is a very complex natural system.

In this therapy, the ultrasonic waves generated by the dolphins have a certain frequency that can align the work function of motor and sensory nerves with autism [3]. This method has proven successful for people with autism more results for people with autism become more effectively and four times faster than other therapies.

According to the latest report from [4], dolphin therapy has a very good effect on children with autism. According to the observation of autistic individuals by [5], that the fine and gross motor function of children, learning, cognitive abilities, concentration and communication, as well as the ability to interact with others will be better.

Many people with autism do not have the opportunity to enjoy the dolphin therapy, because it takes extra time to be able to provide direct therapy in which the patient must deal directly with the dolphins in the treatment and requires a significant financial cost for one treatment, therefore, a research on producing the similar ultrasonic waves suitable for autismtion therapy is proposed. However, the literature on research of utilization on the artificial wave of ultrasonic 
dolphin for autism therapy is not yet reported until now.

In this study, firstly, whole samples of dolphin sounds are recorded while autism therapy takes place on Dolphin Therapy Ocean Dream Samudera Ancol. Secondly, this sound sample is trimmed into several sound samples. Then, the sound samples are edited in order to reduce the noises by removing unnecessary background noises and improving dolphin sounds. Inter-frequency, period graph and power spectral density is characterized from the resulted sound signals. At this stage of research, a model of ultrasonic waves for autism therapy is developed and simulated to evaluate its performance for uses in the treatment of patients with autism.

\section{STUDY LITERATURE}

Bottlenose dolphins (Tursiops truncates) are a small type of the Cetacea order which lives in coastal waters and usually performs on stage (figure 1). This mammal is characterized by relatively straight and firm posture, large-sized snout and is clearly separated from the melon by a layer. The dorsal fin is high with somewhat curved like end, emerges from the mid-back [6].

\section{A. Behavior of Dolphins}

The dolphins perform various movements and behavior associated with their life. Its well-known activity is breaching of which dolphins will jump into the air with the head first and flopped back into the water. Breaching activity is a sign of an attempt to eliminate parasites attached to its body, show of force, just pleasure and a form of communication in their group [7]. Bow-riding is an performed by swimming dolphins to follow the waves caused by the movement of the ship and following the ship. Spyhop is raising its head to the water surface that serves to observe the ambient conditions because visibility is further in the air than in the water [8]. Lob-tailing is lifting flux or tails of dolphins in the water associated with dolphin aggressiveness dolphins in communication [7].

According to [9], the dolphin has a social behavior that is characterized by:

Greeting: dolphin always greets each other when it meets its group by fast swimming towards on the water surface while moving its tail or making sounds.

Roughhousing: Dolphin welcomes the newborn child by making noises. It uses its rostrum and flukes.

Alloparental care: Young dolphins swim and play with other adult dolphins for more than 1 hour when their mother is foraging at a distance of several hundred meters from them. The Use of Voice Dolphins.

\section{B. The Use of Voice Dolphins}

The role of sound is very important for marine mammals, because the sound can propagate in the water five times faster than in the air and have a wider range of communication than the sight [10]. Bioacoustics is the study of sounds produced by animals. Acoustics is the tool most effective and efficient way to communicate with the aquatic environment because of the sound in water is $1500 \mathrm{~m} / \mathrm{s}$ or 4,5 times faster than the speed of sound in air.

According to [11], dolphins sounds can be grouped into three types, namely (1) click for echolocation, (2) the burst is described as shrill or barking, (3) the whistle is used for communication.

Table 1. The range of frequencies produced by several species of cetaceans of the sub order odontoceti

\begin{tabular}{|c|c|c|c|c|c|}
\hline \multirow[b]{2}{*}{ Spesies } & \multicolumn{2}{|c|}{ Mlinimum Threshold } & \multirow[b]{2}{*}{$\mathrm{f}_{0}(\mathrm{kHz})$} & \multirow[b]{2}{*}{$\mathrm{f}_{\max }(\mathrm{kHz})$} & \multirow[b]{2}{*}{ Reference } \\
\hline & $(\mathrm{mPa})$ & $\mathrm{Nms}^{-1}$ & & & \\
\hline $\begin{array}{l}\text { Bottlenose dolphin (Tursiop } \\
\text { truncates) }\end{array}$ & 0,1 & 0,06 & 50,0 & 115,0 & \begin{tabular}{|l} 
Jonson (1967) \\
\end{tabular} \\
\hline Killer whale (Orcineus Orca) & 0,02 & 0.013 & 15,0 & 31,0 & Hall and Jhonson (1972) \\
\hline $\begin{array}{l}\text { River dolphin (Inia } \\
\text { geoffrensis) }\end{array}$ & 0,32 & 0,21 & 30,0 & 100 & Jacobs and Hall (1972) \\
\hline Ringed Seal (Pusa hispida) & 2,6 & 1,7 & 40,0 & 55,0 & \begin{tabular}{|l}
$\begin{array}{l}\text { Terhune and Ronald } \\
(1975)\end{array}$ \\
\end{tabular} \\
\hline $\begin{array}{l}\text { Hawaaiian monk Seal } \\
\text { (Monacus Schauinslandi }\end{array}$ & 1.8 & 1,2 & 16,2 & 30,0 & Thomas et al. (1990) \\
\hline $\begin{array}{l}\text { West Indian Manatee } \\
\text { (Trichechus Manatus) }\end{array}$ & 0,38 & 0,25 & 18,0 & 30,0 & Gerstein etal. \\
\hline
\end{tabular}


At depths greater than 200 meters where light cannot penetrate the sea marine mammals such as dolphins would rely on sound than light as a major tool in communication and be more careful of the surrounding environment.

\section{Echolocation}

Echolocation is the ability of animals to produce a moderate or high frequency and detect echoes of the sound to determine the distance of an object and to recognize physical presence in the vicinity. Echolocation provides detailed and accurate information about the surrounding conditions and produces high frequency [12].

Marine mammals are capable of echolocation usually have a remarkable ability to distinguish fine detail objects. This is presumably because the skull bones have been arranged to form a parabolic reflector that focuses the sound on the forehead. Organs lens-shaped waxy (melon) and is located in the forehead will focus on the sound produced nasal plugs so that the sound will be emitted back in the direction desired by the marine mammals. At the same time, the sound waves reflected from the object will be re-routed through a channel that contains fatty oils and is located in the lower jaw to reach the inner ear. Distribution of sound can be made more precise and meticulous with the help of a bubbly froth [13].

The Author [11], states that the tools for producing and receiving dolphin sound in the area of echolocation have already been highly developed, like the use of ultrasonic (sonar) to estimate the depth of the sea. Sound in ultrasonic echolocation is transmitted towards a particular direction and smoothly travels in water. When this wave hits an object, it will be reflected back to the source.

\section{RESEARCH METHODOLOGY}

A. Patterns of ultrasonic waves generated by the dolphins for autism therapy

Sound samples from dolphins (figure 1) were obtained from underwater hydrophones and recorded using a digital recorder connected to the amplifier from the hydrophones. Hydrophones were lowered at a depth of 2-3 meters of water surface in accordance with the visual observation. These sound samples are stored as a raw sound file of WAV-extension and analyzed in Wavelab software. Analysis was carried out to determine the spectrum analyzer frequency of dolphin sounds while doing therapy to people with autism and will be compared when the dolphins are not doing therapy.

Analysis performed to determine the spectrum analyzer frequency dolphin sounds while doing therapy to people with autism and will be compared when the dolphins are not doing therapy.

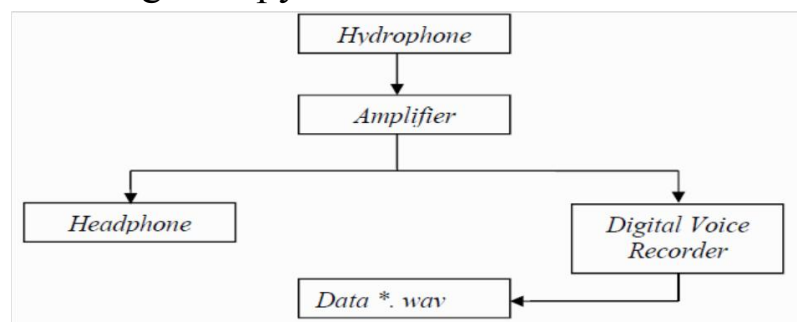

Fig 1. The flow of sound sampling

\section{B. Detecting and analyzing the characteristics of ultrasonic waves generated by dolphins on several conditions.}

In this stage, the original signal from dolphin sounds are improved by removing background noises created by water and breathing sounds from a dolphin (hiss and noise reduction). Long recorded samples are cropped so only important sounds from dolphin are recorded. Periodogram of functions between frequency and Power Spectral Density (PSD) of dolphin sounds are constructed. 
IV. RESULTS AND DISCUSSION

A. Dolphin therapy Against Autism Patients under conditions of hydrophones Low cut off for 48 minutes of observation time

Figure 2 shows the original signal frequency spectrum taken from a therapy session with dolphin without any modification.

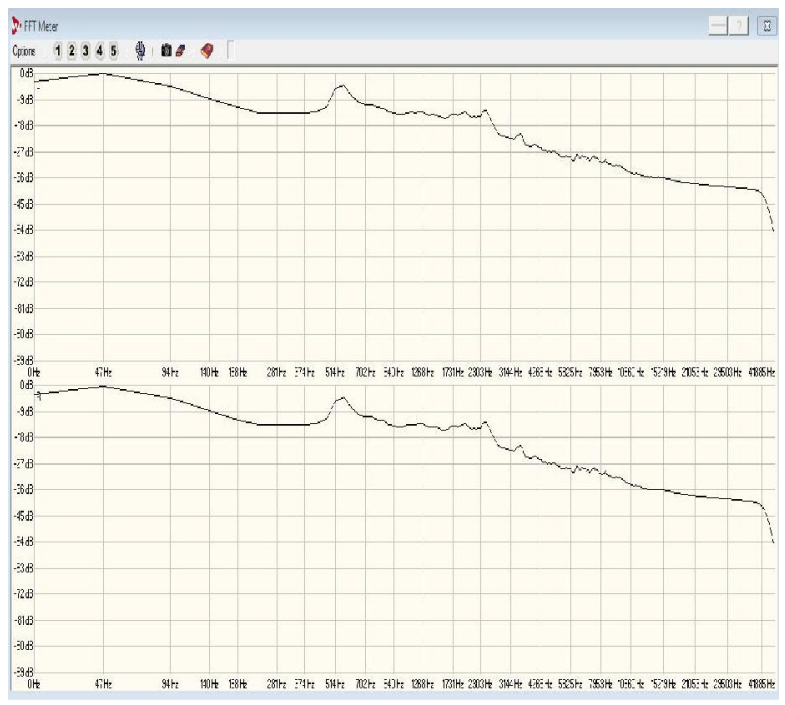

Fig 2. Frequency spectrum of the original sound signal when the therapy progresses (low cutoff) without detection and error correction

Figure 3, shows the frequency spectrum with error detection

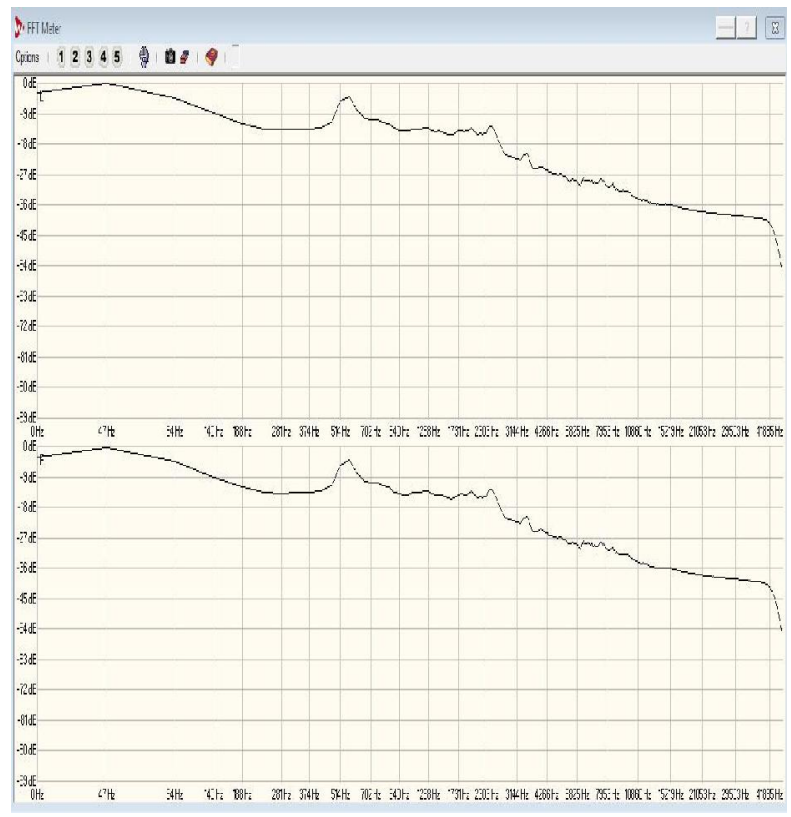

Fig. 3. Frequency spectrum of the original sound signal when the therapy progresses (low cut off) with error detection
Figure 4, shows the frequency spectrum with error correction

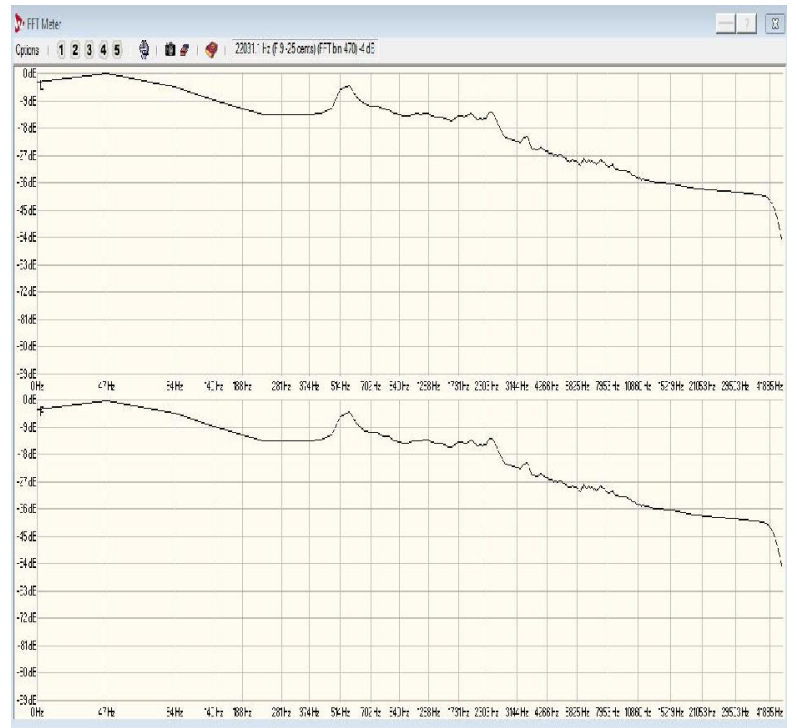

Fig. 4. Frequency spectrum of the original sound signal when the therapy progresses (low cut off) with error correction

\section{B. Dolphin Therapy Against Autism Patients}

a Low cut on hydrophones conditions for 60 minutes of observation time

When the original voice signal processing therapy progresses (low cut on). At this signal has not been made detection and error correction.

Frequency Spectrum of the original sound generated from the voice signal can be seen in figure 5 .

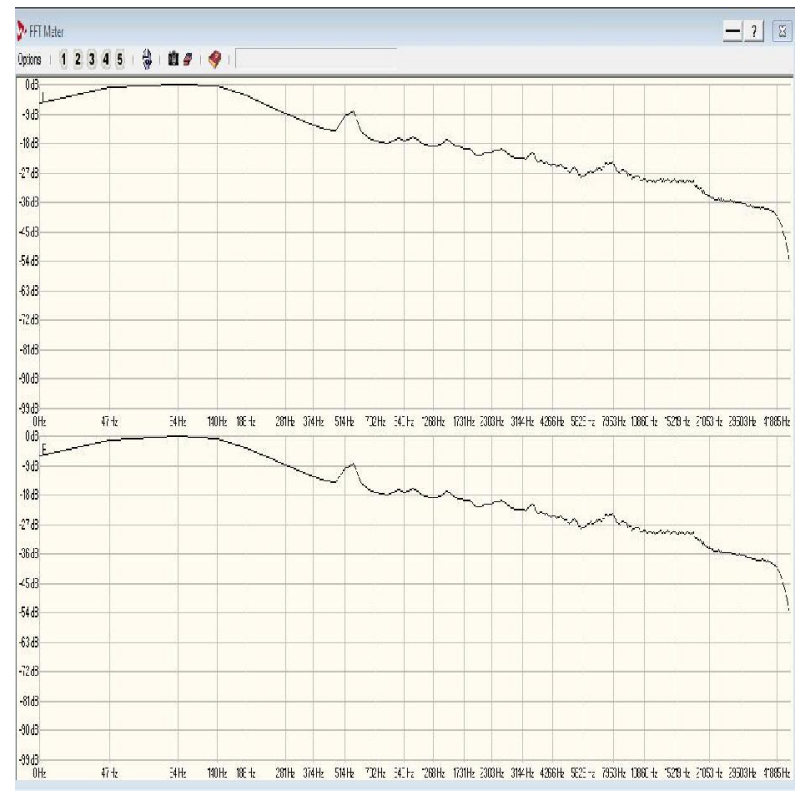

Fig. 5. Frequency spectrum signal when original sound therapy in effect (low cut on) without error detection and correction 
Frequency spectrum with error detection can be seen in figure 6 .

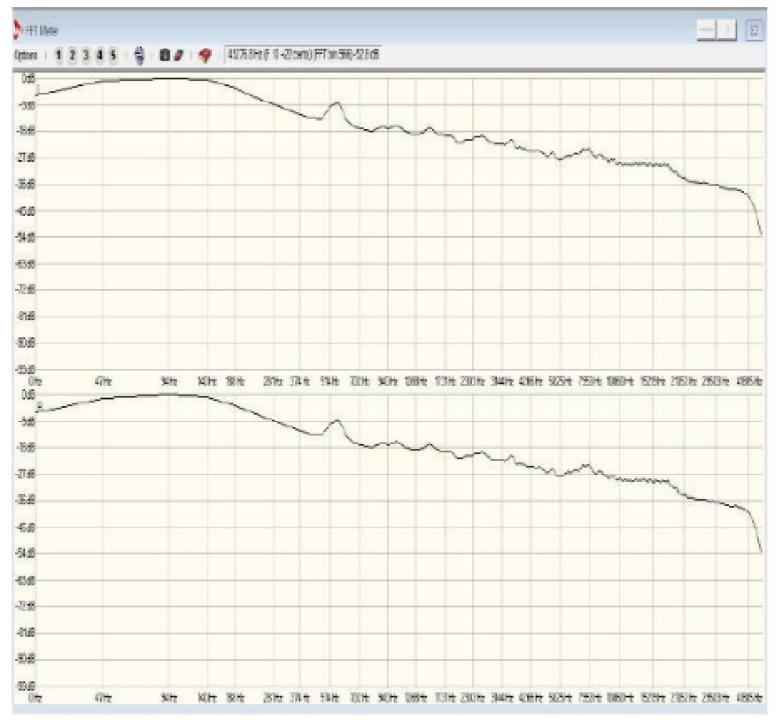

Fig. 6. Frequency spectrum signal when original sound therapy in effect (low cut on) with error detection

Figure 7, shows the frequency spectrum with error correction

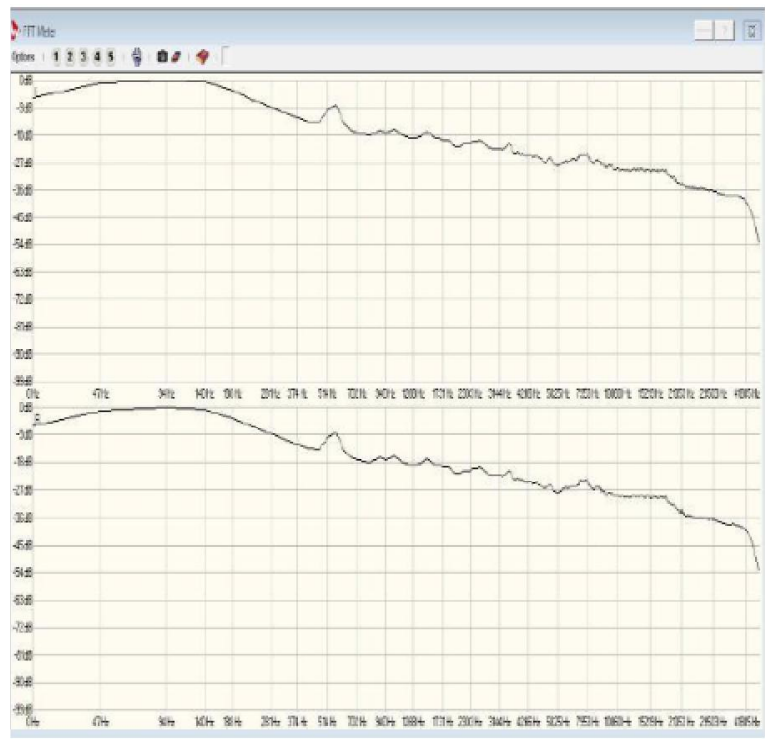

Fig. 7. Frequency spectrum signal when original sound therapy in effect (low cut on) with error correction

C. Observation Against Dolphins without the patient in a state of hydrophones Low Cut Off for 20 minutes of observation time

When the original voice signal processing without the patient (low cut off). At this signal has not been made in error detection and correction.
The frequency spectrum of the original sound produced is shown in figure 8 .

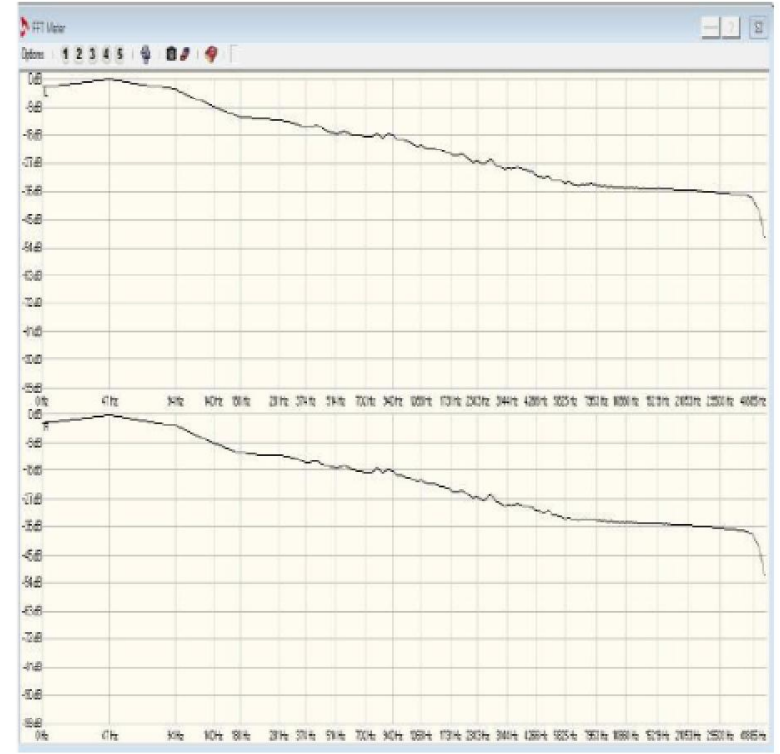

Fig. 8. Frequency spectrum signal dolphin sounds without patient (low cut off) and without error detection and correction

An original voice signal processing without the patient (low cut off). At this signal has been made error detection and correction.

Figure 9, show the frequency spectrum with error detection

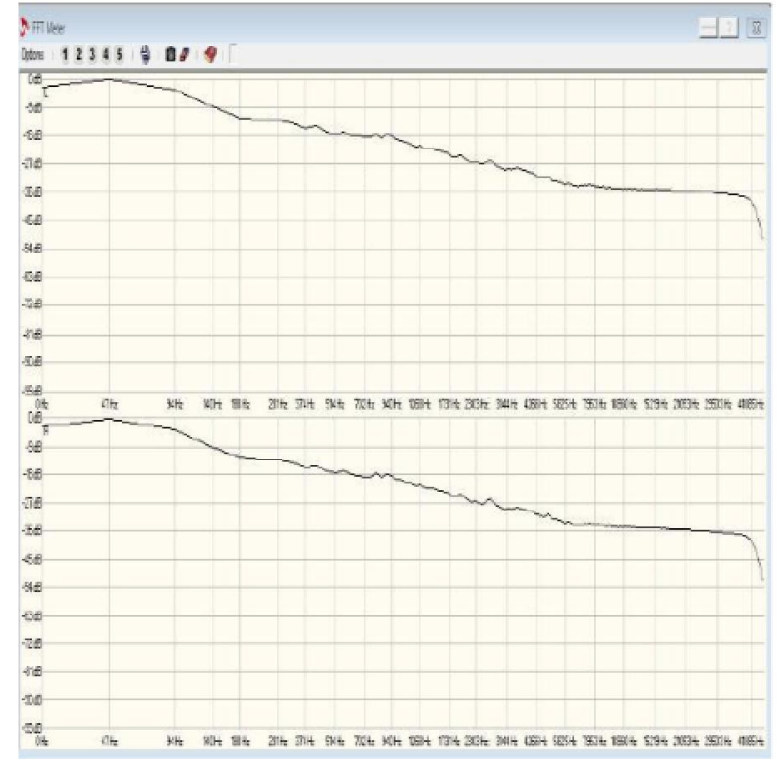

Fig. 9. Original sound frequency Spectrum signal dolphins (low cut off) with error detection 
Figure 10, show the frequency spectrum with error correction

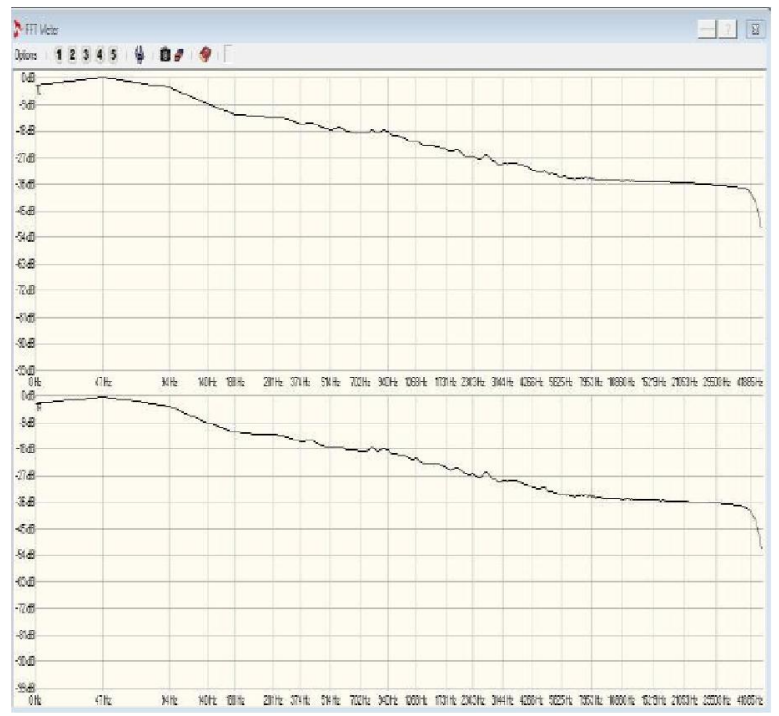

Fig. 10. Original sound frequency Spectrum signal dolphins (low cut off) with error correction

\section{Observations against dolphins without the} patient in a state of Hydrophone Low cut on a 20 minute observation time

When the original voice signal processing without the patient (low cut on). At this signal has not been made in error detection and correcting.

The frequency spectrum of the original sound produced is shown in figure 11

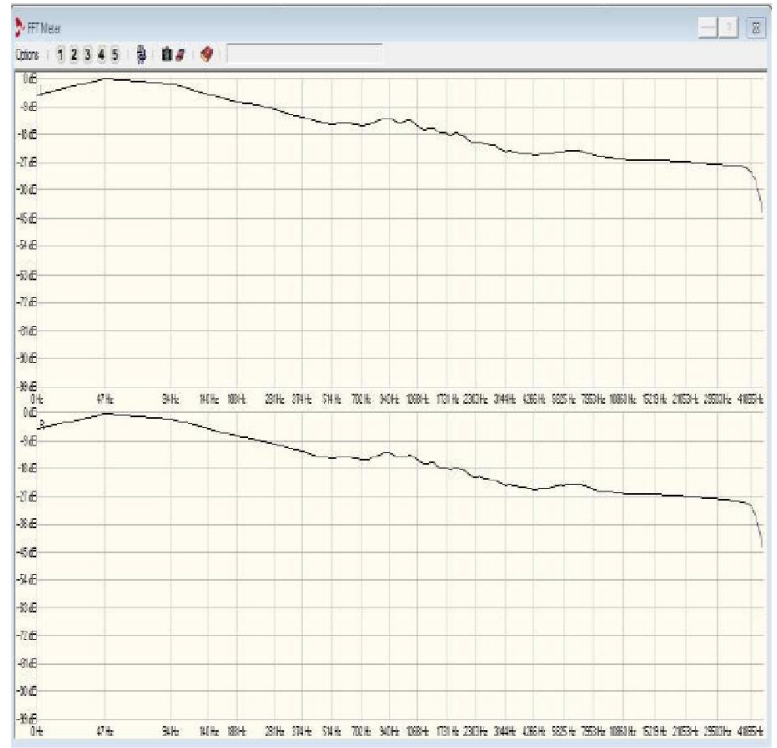

Fig. 11. Original sound frequency Spectrum signal no patient (low cut on) and without error detection and correction
When the original voice signal processing without the patient (low cut on). At this signal has been made error detection and correction.

Frequency spectrum signal with error detection is shown in figure 12

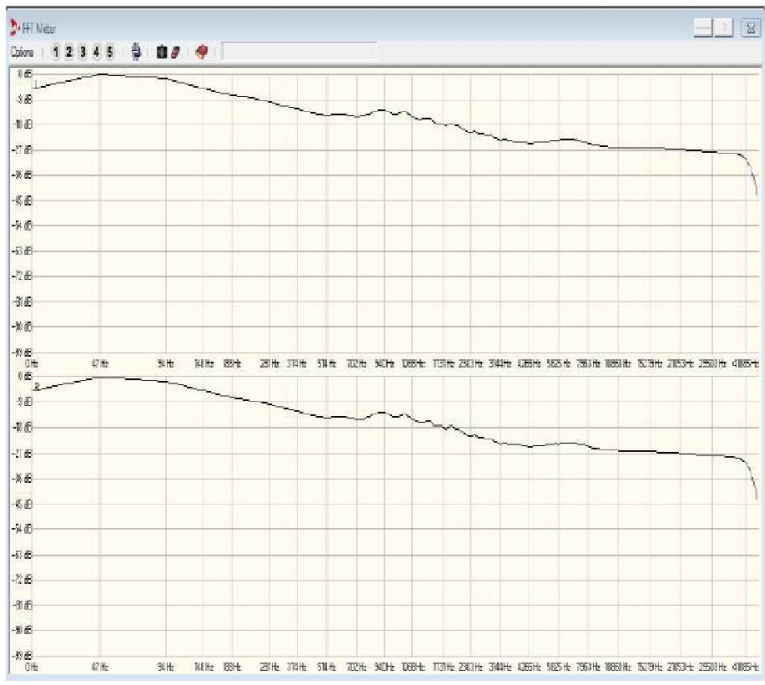

Fig. 12. Original sound frequency spectrum signal dolphins (low cut on) with error detection

Frequency spectrum signal with error correction is shown in figure 13

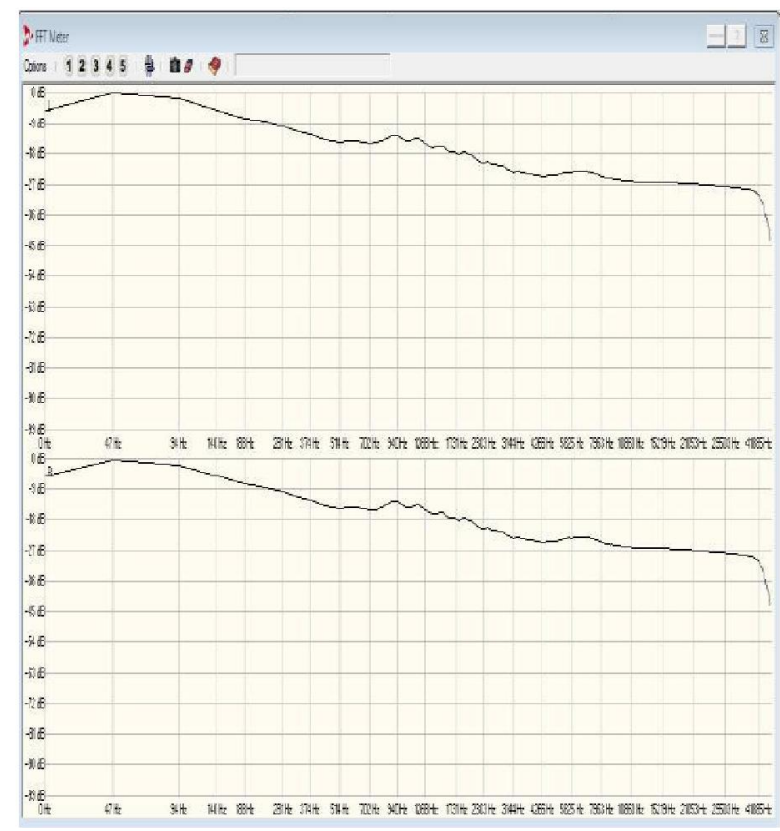

Fig. 13. Original sound frequency spectrum signal dolphins (low cut on) with error correction

\section{CONCLUSION}

After this first year research, several conclusions can be drawn:

1) Frequency of sound waves generated by dolphins during a therapy session under hydrophone low cutoff is $47953.13 \mathrm{~Hz}$ 
with left channel gain is $46.3414 \mathrm{~dB}$ and right channel gain is $46.4340 \mathrm{~dB}$. When hydrophone is low cut on, the frequency is $47953.13 \mathrm{~Hz}$ with left channel gain is $45.5928 \mathrm{~dB}$ and right channel gain is $45.6809 \mathrm{~dB}$.

2) Frequency of sound waves generated by dolphins without therapy session under hydrophone low cutoff is $47953.13 \mathrm{~Hz}$ with left channel gain is $44.7439 \mathrm{~dB}$ and right channel gain is $45.0014 \mathrm{~dB}$. When hydrophone is low cut on, the frequency is $47953.13 \mathrm{~Hz}$ with left channel gain is $45.025 \mathrm{~dB}$ and right channel gain is $45.1104 \mathrm{~dB}$.

3) Acoustic frequency spectrum identified to be useful for autism therapy from our observation is within the range of 1218.75 $\mathrm{Hz}$ to $47953.13 \mathrm{~Hz}$. This shows that dolphins generate audio and ultrasonic waves in stimulating autism patients. The ultrasonic waves create different tones with 0.02 second intervals for a resolution of 1024 bits.

4) Dolphin therapy for children with special care, including children with autism is a combination of behavioral therapy and communication therapy, where the dolphin is a subject involved in the interaction.

5) Dolphin therapy shows positive changes such as self-confidence, eye contact and emotions to patients after having stimulation.

\section{REFERENCES}

[1] Baron-Cohen, S, \& Howlin, P, "The theory of mind deficit in autism: some questions for teaching and diagnosis. In Baron-Cohen, S, Tager-Flusberg, H, 21 \& Cohen, D.J. (Eds) Understanding other minds: perspectives from autism. Oxford University Press, 1993.

[2] Power. Michel.D, "Children with Autism," Woodbine House, 1989.

[3] Michael T. Hyson, Ph.D.,"Dolphins, Therapy \& Autism,” 2011.
[4] Brensing, K., Linke, K., Todt, D., "Can dolphins heal by ultrasound?, " Journal of Theoretical Biology, Volume 225, pp. 99$105,2003$.

[5] Wein-Carrie, "Effect of ultrasound on completionof cognitive tasks in relation to dolphin assisted therapy,"

[6] Jefferson, T.A, S. Leatherwood, M.A. Webber. "FAO Species Identification Guide. Marine Mammals of The World,“ UNEP-FAO. Rome, pp.320,1993.

[7] Carwadine, M. "Eye Witness Handbook: Whales, Dolphins and Porpoises. The Visual Guide to All World's Cetacean. Dorling Kindersley Ltd. New York,p. 256, 1995.

[8] Carwadine, M., E.Hoyt, R.E. Fordyce, P. Gill. "An Australian Geographic Guide to Whales, Dolphins and Porpoises," Australian Geographic Press. Australia, p. 40, 1997.

[9] Shane, H., "Behavior and Ecology of The Bottlenose Dolphin at Sanibel Island, Florida. In: S. Leatherwood, S. And R.R.Reeves," The Bottlenose Dolphin Academic Press, Inc.San Diego, California, United States of America,pp.235-245,1990.

[10] Nybakken, J.W. "Biologi Laut : Suatu Pendekatan Ekologis," PT. Gramedia.Jakarta, 1992.

[11] Caldwell, M.C. And D.K. Caldwell. "Review of the Signature-Whistle Hypothesis for the Atlantic Bottlenose Dolphin. In: S. Leatherwood, S. And R.R.Reeves," The Bottlenose Dolphin. Academic Press, Inc.San Diego, California, United States of America, pp. 203-234,1990.

[12] Supangat. A, "Pencemaran Suara di Laut," IPTEK. Inovasi Vol.6/XVIII/Maret. Jakarta, pp.16-22,2006.

[13] Evans, P.G.H. "The Natural History of Whales and Dolphin," Christoper Helm Ltd, Imperial House, England, pp.188-205, 1987. 